narrative reflected in his write up although, like everybody else, I have my own.

There is an old wine in a new bottle in all these discussions and narratives. The old wine is what prehistoric man and ancient civilisations perceived as 'spirit', as it is not difficult to imagine that a 'spirit' or anything 'spiritual' must reflect a story or narrative, the beginning of which must have a purpose (known or unknown) and the end a meaning that 'loops back' onto the purpose at the beginning. Everything about the human mind will be pointless, as some intellectuals say about the universe, unless it is centred on 'meaning.' There is no need to bring in Wittgenstein's legacy since we can figure this out ourselves from scratch. The ongoing recording or tape of our individual experiences (consciousness) is what forms our memory, which itself determines all future thinking and moment-by-moment definition of reality. The process of our minds determining or defining reality on a moment-bymoment basis is what we call (ordinary) perceptions. What is significant about this old wine, however, is that these recordings or narratives are intergenerational, ancestral and ultimately biological (DNA-based). Therefore even emotions and instincts represent forms of narratives, because they are the stories and instruction our ancestors continue to tell us that allow us to perceive without previous individual experience of what we 'just know' or feel. In response to Jeremy Holmes's letter, 'What about psychodynamics?', ${ }^{2}$ I suppose it is now obvious that Freudian psychoanalysis and whatever psychodynamic psychotherapy and interpretations that we come up with can only represent the individual and/or culturally shared narrative. To the average Itsekiri (my fellow tribesman), psychoanalysis would be meaningless unless this Itsekiri person is tutored in Western culture and psychoanalytic narratives. For education and training purposes it is important, as stated in the adult psychiatry curriculum of the Royal College of Psychiatrists, ${ }^{3}$ that trainees should be 'able to appreciate the "scientific unknowns" in the relevant field of psychiatric practice'. To be able to do this the trainee needs to be encouraged to see the movie (narrative or story) on the DVD and not the chemical constituents of the DVD, the mechanism of the DVD player or description of its casing. Here is the secret of the so-called 'mind-brain problem' resolved in part. Each new generation comes with a new narrative worth listening to as part of the clinical encounter. It is unlikely that the impersonal biological DVD player (the brain) and its mechanisms, like those of other animals, will physically change much over a generation, but the narratives (the movies or stories held on the DVD or tape) that give meaning to people's lives - their spirituality - will continue to change and evolve for as long as the species exists.

In our consensus approach to patient consultation, the word 'narrative' may be more acceptable than 'spirituality' as it has no direct association with religion (something that one should rightly be suspicious of), but if 'meaning' is what we aim to centre consultations on, then it is important to understand that underneath the various terms we use, a 'meaning-centred approach' must be the same as spirituality and psychiatry.

1 Wallang, P. Wittgenstein's legacy and narrative networks: incorporating a meaning-centred approach to patient consultation. Psychiatrist 2010 34: 157-61.
2 Holmes J. Meaning centred approaches: what about psychodynamics? Psychiatrist 2010; e-letter (http://pb.rcpsych.org/cgi/eletters/34/4/ 1579964).

3 Royal College of Psychiatrists. A Competency Based Curriculum for Specialist Training in Psychiatry: Specialist Module in Adult (General and Community) Psychiatry. Royal College of Psychiatrists, 2009 (http://www.rcpsych.ac.uk/PDF/Adult_(General_and_Community)_ Feb09.pdf).

Temi Metseagharun, Staff Grade Psychiatrist, Robertson Centre, Kidderminster General Hospital, Bewdley Road, Kidderminster DY11 6RJ, email: drtemi2008@gmail.com

doi: $10.1192 / p b .34 .9 .404 b$

\section{Better definitions of concepts}

If you talk to a man in a language he understands, that goes to his head. If you talk to him in his language, that goes to his heart.

Nelson Mandela

In their article on religion, spirituality and mental health, Dein et al have made some very important points. As health professionals, we are encouraged to become competent in our understanding of the role of culture and religion in the mental illness phenomenon but at the same time our effort to reach such understanding could be perceived in a negative light.

We seem to restrict our definition of spirituality. In my search for better understanding I have found the following definition by Murray \& Zentner ${ }^{2}$ very helpful: 'in every human being there seems to be more a spiritual dimension, a quality that goes beyond religious affiliation that strives for inspiration, reverence, awe, meaning and purpose, even in those who do not believe in God. The spiritual dimension tries to be in harmony with the universe, strives for answers about the infinite, and comes essentially into focus in times of emotional stress, physical (and mental) illness, loss, bereavement and death'. This has suggested several important implications for my clinical practice; especially, how I can incorporate this meaning in the patients' understanding of their mental illness in relation to their spirituality. The individual patient approach employed by Western-trained psychiatrists and other mental health workers may fall short of what the patient expects in some cases, as a result of our ignorance of this important aspect.

1 Dein S, Cook CCH, Powell A, Eagger S. Religion, spirituality and mental health. Psychiatrist 2010; 34: 63-4.

2 Murray RB, Zentner JP. Nursing Concepts for Health Promotion. Prentice Hall, 1989: 259.

Ibtihal Elshikh, ST4 in Child and Adolescent Mental Health Services, East of England Deanery, Hemel Hempstead, email: ibtihal_agha@hotmail.com

doi: $10.1192 / p b .34 .9 .401$

\section{It's belief systems that keep us healthy, not religion}

Dein et al appear to believe, on the basis of suggestive but by no means overwhelming evidence, that religious belief is associated with good mental health. Bruno Bettelheim, in his account of his concentration camp incarceration, ${ }^{2}$ noted that those who survived best were those with firmly held beliefs and ideology. Devout Jews and committed Marxists (atheists all) survived longer than those without a belief system. It is not religion as such that saves, but - however derived - a sense of community and connection, and the capacity to put even 